\title{
INTERNAL CONTROL STRATEGY OF BEVERAGE BUSINESSES IN THAILAND: EFFECTS ON GOAL ACHIEVEMENT
}

Krittayawadee Gatewongsa, Mahasarakham Business School Mahasarakham University, Thailand Phapruke Ussahawanitchakit, Mahasarakham Business School Mahasarakham University, Thailand

\author{
dx.doi.org/10.18374//JBS-13-3.7
}

\begin{abstract}
This research aims at investigating the effects of internal control strategy on goal achievement through the mediating influences of internal audit efficiency, operational risk reduction, corporate management effectiveness, and firm value increase. Internal control strategy consists of regulation compliance awareness, internal control knowledge integration, best internal control implementation, and risk control effectiveness. The data were collected by survey questionnaires administered to the internal audit managers of beverage businesses in Thailand of which 96 completed questionnaires are used in the analysis. The results of OLS regression analysis show that regulation compliance awareness, internal control knowledge integration, and risk control effectiveness have a significant positive effect on firm value increase. In addition internal audit efficiency, corporate management effectiveness, and firm value increase have a significant positive association with goal achievement. Likewise, employee knowledge, resource efficiency, and environmental uncertainty are the antecedents of internal control strategy. Moreover, the results show that organizational experiences are not the moderating variables. The implications, suggestions for further research, and limitations are discussed.

Keywords: Internal Control Strategy; Regulation Compliance Awareness; Internal Control Knowledge Integration; Best Internal Control Implementation; Risk Control Effectiveness; Internal Audit Efficiency; Operation Risk Reduction; Corporate Management Effectiveness; Firm Value Increase, Goal Achievement, Executive Vision, Employee Knowledge, Resource Efficiency, and Environmental Uncertainty.
\end{abstract}

